\title{
Malatya'da Meyve Fidanı Yetiştiriciliğinin Durumu, Sorunları ve Çözüm Önerileri
}

\author{
Hüseyin KARLIDAĞ $\breve{G}^{1}$, Salih ATAY², Firat Ege KARAAT ${ }^{1}$, Tuncay KAN ${ }^{1}$, Hakan YILDIRIM ${ }^{1}$
}

ÖZET: Malatya'da 2015 y1lında yürütülen bu çalışmada, ilde fidan üretimi yapmakta olan 16 farklı üretici ile yüzyüze görüşülerek ve bu üreticilere ait fidan üretim alanları incelenerek elde edilen veriler çerçevesinde, Malatya ili fidancilık durumunun belirlenmesi amaçlanmıştır. Elde edilen verilere göre, ildeki fidan üretim işletmelerinin küçük ölçekli ve yaklaşı \%90'ının 50 da ve daha küçük üretim alanına sahip oldukları belirlenmiștir. Üretim durumları incelendiğinde; üretimin 1/3'ünü kayısı fidanı oluştururken, bunu elma, kiraz, armut ve badem fidanı izlemektedir. Üretilen fidanların \%66.81'i Malatya'da, geri kalanı çevre illerde pazarlanmaktadır. Sertifikalı meyve fidanı fiyatı ortalama olarak 4.87 TL olarak bulunurken, en yüksek fiyat 6.5 TL ile kiraz fidanında tespit edilmiştir. Fidan üreticileri, üretimle ilgili süreçte önemli bir sorun olmadığını belirtirken, üretici birliklerinin olmayışı, sertifikasız ve kontrolsüz fidancıların varlığı ve maliyet ile fiyat arasında bir denge oluşturulamaması problem olarak vurgulanmıştır.

Anahtar Kelimeler: Anaç, aşı, fidan yetiştiriciliği, işletme büyüklüğü

\section{Situation, Problems and Suggestions for Fruit Sapling Growing in Malatya}

\begin{abstract}
In the present study which was conducted in Malatya in 2015, the situation of seedling production was aimed to be determined by interviewing with the growers and visiting the nurseries. As a result of the study, nurseries were found to be small scaled and approximately $90 \%$ of them have 50 da or smaller production areas. When the production of the nurseries were analyzed, apricot seedlings was found to constituted $1 / 3$ of the total seedling production and it was followed by apple, cherry, pear and almond seedling production. $66.81 \%$ of the seedlings are sold in Malatya and the rest are marketed to nearby cities. The average price for certified fruit seedling was found as $4.87 \mathrm{TL}$ and the highest price was determined in cherry seedlings with the price of $6.5 \mathrm{TL}$. While seedling growers haven't observed any important issues in seedling production, the lack of grower associations, the facts of pirate seedling growers and balance between costs and prices could not have been constituted are emphasized as the main problems.
\end{abstract}

Keywords: Rootstock, grafting, sapling growing, farm size

Hüseyin KARLIDAĞ (0000-0002-9317-8021), Frrat Ege KARAAT (0000-0002-4676-0721), Tuncay KAN (0000-0002-3584-5279), Hakan YILDIRIM (0000-0002-8130-5417), İnönü Üniversitesi, Ziraat fakültesi, Bahçe Bitkileri Bölümü, Malatya, Türkiye Salih ATAY (0000-0002-9361-9755), T.C. Gıda Tarım ve Hayvancılık Bakanlığı, Meyve Araştırma Enstitüsü, Malatya, Türkiye Sorumlu yazar/Corresponding Author: Hüseyin KARLIDAĞ, huseyin.karlidag@inonu.edu.tr 


\section{GİRİș}

Türkiye 16.9 milyon tonluk yaş meyve üretimiyle dünyada \%2.3'lük paya sahip olup, 10. sırada yer almaktadır (Anonim, 2014). Meyvecilik, Türkiye'de ve Malatya'da yaygın olarak yapılan önemli bir tarımsal faaliyet alanı olup, başlangıç materyali olan fidan üretimiyle başlamaktadır. Fidancılık ülkemizde hızla büyüyen bir işletme kolu olup, her yıl milyonlarca meyve fidanı üretilmektedir. Fidan üretimi yoğun işgücü ve zaman gerektirmekte ve her bir aşaması kritik bir önem teşkil etmektedir. Örneğin anaç üretimi için kullanılacak tohumlardaki çimlenme oranından başlayarak, vejatatif gelişme, aşı tutma oranı ve fidan gelişme ve dallanma özellikleri gibi parametreler fidancıllı̆̆n başarısını belirlemektedir.

Türkiye'de başlangıçta, meyve ve asma fidanı üretiminin önemli bir bölümü kamu işletmelerinde üretilirken, günümüzde fidan üretiminin çok büyük bir kısmı özel sektör fidancılık işletmeleri tarafından yapılmakta ve bunun sonucunda da farklı yörelerde özel sektör fidancılık işletmeleri yaygınlaşmaktadır (Gençtan ve ark., 2003). 2002 y1lında fidan üretiminin \%16'sını karşılayan kamu işletmelerinin, 2010 yılındaki payı \%2.5'e kadar düşmüştür (Büyükarıkan ve Büyükarıkan, 2014). Kamu sektörünün fidan üretimindeki payının azalması ve Gıda, Tarım ve Hayvancılık Bakanlığ 1 tarafından sertifikalı fidan kullanımının desteklenmesiyle, fidan üretiminde önemli artışlar sağlanmıştır. Gıda, Tarım ve Hayvancılık Bakanlığ 1 verilerine göre; 2002 yılında 2 420730 adet olan meyve fidanı üretimi 2014 y1lında 58384744 adete yükselmiştir. Bu yıllar arasında en yüksek üretim miktarı 2007 yılında 64230921 adet olarak gerçekleşmiştir. Bu üretim değerlerine kayıt altına alınamayan fidanların dahil olmaması gerçeği de gözardı edilmemelidir. Üretimdeki bu artışlara karşın, Türkiye'de meyve ve asma fidancılığında devam eden plansız ve dağınık yapılaşma, özellikle üretimde kalite yönüyle istikrarsız ve yetersiz bir tabloyu yansıtmaktadır (Söylemezoğlu ve ark., 2010).

Türkiye fidan üretiminde \%39 pay ve y1llık 25 milyon adet üretim ile Akdeniz Bölgesi ilk sırayı alırken, ikinci sırayı \%19'luk paylarla Ege ve Marmara Bölgeleri izlemektedir. Doğu Anadolu Bölgesinin üretimdeki oranı ise sadece $\% 2$ 'dir. İllere göre fidan üretimi incelendiğinde ise; Isparta ili \%21.2 ile ilk sirada yer almakta, bunu sirasiyla; \%11.1 ile Bursa, \%9.1 ile Manisa, \%6.1 ile Hatay, \%5.3 ile Aksaray, \%4.6 ile Balıkesir takip etmektedir (Anonim, 2012).

Yukarıdaki veriler, Malatya'nın meyve fidanı üretimi alanında istenilen seviyede olmadığının bir göstergesidir. Ancak bulunduğu konum ve sahip olduğu ekolojik yapı Malatya için büyük bir potansiyel oluşmasına vesile olmaktadır. Söz konusu bu çalışma ile Malatya' da bulunan fidan işletmelerinin yapıları, mevcut durumları, üretimleri, pazar durumları, işletmelerin sorunları ve bunlara yönelik çözüm önerileri ortaya konulmaya çalışılmıştır. Fidan işletme sahipleri ile yüz yüze görüşülerek ve fidanlık alanları incelenerek elde edilen verilerle ilin fidan üretim durumu, sorunları ve çözüm yollarının belirlenmesi hedeflenmiştir.

\section{MATERYAL VE YÖNTEM}

Bu çalışma, 2015 yılı Malatya İl Gıda Tarım ve Hayvancılık Müdürlüğü kayıtlarına göre fidan üretimi yapan 16 işletmede yürütülmüştür. İşletme sahipleri ile Mayıs ve Haziran 2015'te yüz yüze görüşülerek ve fidan üretim alanları gezilerek veriler elde edilmiştir.

İldeki 16 adet fidan üreticisiyle yüzyüze görüşülerek alınan bilgilere göre değerlendirme yapılmıştır. Fidan üreticilerine fidan işletme büyüklükleri, fidan üretimi, pazarlama ve karşılaşılan sorular ana başlığ 1 altında toplam 20 soru sorulmuştur. Toplanan veriler analiz edilerek yorumlanmıştır.

\section{BULGULAR VE TARTIŞMA}

\section{Fidanlıkların İşletme Büyüklükleri}

Çalışmanın gerçekleştirildiği 16 işletmede, ortalama işletme büyüklüğü $42.73 \mathrm{da}$, ortalama parsel büyüklüğü ise 20.73 da olarak belirlenmiştir. İşletmelerin \%37.50'si yani 1/3'ünden fazlas1 30.1 - 40.0 da arasındaki büyüklüğe sahip işletmelerdir. Diğer taraftan, işletmelerin sadece ikisi 20 da üretim alanına sahip iken, 50 dekardan daha fazla üretim alanına sahip işletme sayısı da 1 olup, bu işletmenin büyüklügü 100 da'dır. Isparta ili meyve fidancılığ 1 üzerine yapılan çalışmada, özel sektör fidanlıklarının fidan üretim alanlarının 0,5-190 da arasında değiştiği bildirilmiştir (Yıldırım, 2005). 
Çizelge 1. Fidan üretim işletmelerinin büyüklüklerine göre dağılımı

\begin{tabular}{ccc}
\hline İșletme Büyüklüğ̈̈ (da) & İşletme Sayısı (adet) & Oranı (\%) \\
\hline $0-20$ & 2 & 12.50 \\
$20-30$ & 3 & 18.75 \\
$30-40$ & 6 & 37.50 \\
$40-50$ & 4 & 25.00 \\
50 ve üzeri & 1 & 6.25 \\
Toplam & $\mathbf{1 6}$ & $\mathbf{1 0 0 . 0 0}$ \\
\hline
\end{tabular}

\section{Fidan Üretimi}

Çalışmanın yürütüldüğü 16 fidan işletmesinden 4 tanesi (\%25) üretiminin tamamını sertifikalı olarak gerçekleştirirken, 12 tanesi (\%75) hem sertifikalı hem de sertifikasız üretim yapmaktadır. Sertifikasız fidan üretimlerinin sadece ceviz çöğürüyle sınırlı kaldığı görülmüştür. Çalışmada Malatya ili toplam meyve fidanı üretimi 567190 adet olarak belirlenmiştir (Çizelge 2). İşletmelerde en fazla fidan üretiminin yapıldığı tür kayıs1 (280 000 adet) olurken bunu elma, kiraz ve badem türlerine ait üretimler takip etmiştir. İncelenen işletmelerin tamamı kayısı fidanı üretimi yapmakta iken, dut fidanı üretimini sadece bir işletmenin yaptığı belirlenmiştir.

Sert çekirdekli ve yumuşak çekirdekli meyve türlerinin hemen hemen tamamında fidan üretimi yapilırken; sert kabuklu meyvelerden badem ve ceviz; üzümsü meyvelerden ise dut fidanı üretiminin yapıldığı tespit edilmiştir. Dolayısıyla Malatya ili ve çevre illerin 1lıman iklim meyve türlerinin yetiştiriciliğine uygun olması, fidan üreticilerinin ürettikleri fidanın büyük bir bölümünü Malatya ili ve komşu illere pazarlamaları nedeniyle fidan üretimi 1lıman iklim meyve türleri fidanıyla sınırlı kalmıştır.

Çizelge 2. İşletmelerin meyve türlerine göre fidan üretim miktarları ve üretim yapan işletme sayıları

\begin{tabular}{lccc}
\hline \multirow{2}{*}{ Fidan Türüi } & Fidan Üretimi (adet/işletme) & \multicolumn{2}{c}{ İşletme } \\
\cline { 3 - 4 } Kayıs1 & 17500 & Sayı (adet) & Oran (\%) \\
Elma & 4800 & 16 & 100 \\
Kiraz & 5010 & 13 & 87.50 \\
Erik & 1800 & 12 & 81.25 \\
Şeftali & 2300 & 12 & 75.00 \\
Vişne & 760 & 11 & 75.00 \\
Ceviz & 2050 & 11 & 68.75 \\
Badem & 3250 & 11 & 68.75 \\
Armut & 3100 & 10 & 68.75 \\
Ayva & 750 & 10 & 62.50 \\
Dut & 500 & 1 & 62.50 \\
Toplam & $\mathbf{5 6 7 1 9 0}$ & 16 & 6.25 \\
\hline
\end{tabular}

Çalışmanın yürütüldüğü 16 işletmenin tamamı kayısı, 14 işletme elma, 13 işletme kiraz, 12 işletme erik ve şeftali, 11 işletme vişne-ceviz-badem, 10 işletme armut ve ayva, 1 işletme ise dut fidanı üretimi yapmaktadır (Çizelge 2). 


\section{Fidan üretiminde kullanılan anaçlar}

İncelenen işletmelerin üretimde kullandıkları anaçlar ve bunların kullanım oranları Çizelge 3'de verilmiştir.

Çizelge 3. İşletmelerin meyve türlerine göre kullandıkları anaçlar ve oranları

\begin{tabular}{|c|c|c|c|c|c|}
\hline $\begin{array}{l}\text { Meyve } \\
\text { Türü }\end{array}$ & Kullanılan Anaç & $\begin{array}{l}\text { Kullanım } \\
\text { Oranı (\%) }\end{array}$ & $\begin{array}{l}\text { Meyve } \\
\text { Türü }\end{array}$ & $\begin{array}{c}\text { Kullanılan } \\
\text { Anaç }\end{array}$ & $\begin{array}{c}\text { Kullanım } \\
\text { Oranı (\%) }\end{array}$ \\
\hline Kayısı & Kayısı çöğürü & 100 & Ceviz & Ceviz çöğürü & 100 \\
\hline Şeftali & Şeftali çöğürü & 100 & Erik & $\begin{array}{l}\text { Myrobalan29c } \\
\text { Erik çöğürü }\end{array}$ & $\begin{array}{l}27.27 \\
72.73\end{array}$ \\
\hline Elma & $\begin{array}{c}\text { M9 } \\
\text { MM106 } \\
\text { MM111 } \\
\text { Elma çöğürü }\end{array}$ & $\begin{array}{c}9.13 \\
71.22 \\
8.35 \\
11.30\end{array}$ & Vişne & $\begin{array}{c}\text { Mahlep çöğürü } \\
\text { Vişne çöğürü } \\
\text { Kuş kirazı çöğürü } \\
\text { MaxMa }\end{array}$ & $\begin{array}{l}48.23 \\
18.34 \\
22.27 \\
11.16\end{array}$ \\
\hline Badem & $\begin{array}{c}\text { GF-677 } \\
\text { Badem çöğürü }\end{array}$ & $\begin{array}{l}12.26 \\
87.74\end{array}$ & Kiraz & $\begin{array}{c}\text { Mahlep çöğürü } \\
\text { Kuş kirazı çögürü } \\
\text { MaxMa }\end{array}$ & $\begin{array}{l}44.54 \\
37.16 \\
18.30\end{array}$ \\
\hline Armut & Armut çöğürü & 100 & Ayva & Ayva çöğürü & 100 \\
\hline Dut & Dut çöğürü & 100 & --- & --- & \\
\hline
\end{tabular}

Çizelge 3'de de görüleceği gibi kayısı ve ceviz türleri için anaç olarak işletmelerin tamamı kayısı çöğürü kullanmaktadır. $\mathrm{Bu}$ anlamda Malatya'nın ve bölgenin en önemli meyve türü olan kayısı için çögür anacı haricinde bir anaç arayışının olmadığı anlaşılmaktadır. Elma'da MM106 anacı ön plana çıkarken, kullanım oranı \%71.22 bulunmuştur.

Bodur elma yetiştiriciliğinde giderler oldukça yüksek bir paya sahiptir. Elma üretiminde hastalık ve zararlıların çokluğu, seyreltme gereksinimi, su ve gübre ihtiyacının yanısıra bodur yetiştiricilikte destek ve terbiye sistemlerinin oluşturulmasındaki ihtiyaçlar nedeniyle giderler diğer geleneksel yetiştiriciliğe göre daha fazla olmaktadır (Küçüker ve Özken, 2012). Bu durum üreticilerin tam bodur anaçtan ziyade yarı bodur anaçları tercih etmelerine sebep olmuş olabilir.

Klon anacı kullanımı elmada \%89.70 iken, bu oran diğer türlerde oldukça düşük bulunmuştur. Armut, ayva, kiraz ve erik türlerinde günümüzde klon anacı kullanımı yaygınlık kazanmasına rağmen bölgede halen bu türlerde çöğür anacının tercih edilme oranının oldukça yüksek olması dikkat çekmektedir. Badem, erik ve şeftalide çögür anacı kullanımı yaygın olmakla birlikte, bu türlerde klon anacı kullanımı erikte (\%27.23) diğer iki türe göre daha yüksektir.

Çöğür anacı kullanımının klon anacından daha yüksek olmasının nedeni, fidan işletmelerinin küçük, anaç parsellerinin olmayışı, çiftçilerin anaç konusunda yeterince bilgi sahibi olamamaları, fidan üretiçilerinin klonal anaç üretim yöntemlerini yeterince bilmemeleri ve bunun sonucunda da klonal anaçlarını dışarıdan temin etmeleri sonucu maliyetin artmasından kaynaklandığı düşünülmektedir.

\section{Aşılama}

Çalışmanın bu kısmında aşı yöntemi, aşıya gelme ve aşı tutma oranı olmak üzere 3 kriter üzerinde durulmuştur. İşletmelerin tamamı durgun T göz aşısını kullanmakta olup diğer aşı yöntemleri kullanılmamaktadır. Aşıya gelme ve aşı tutma oranlarına ilişkin elde edilen değerler Çizelge 3'te verilmiştir. 
Çizelge 3. İşletmelerde kullanılan anaçların aşıya gelme ve aşı tutma oranları

\begin{tabular}{ccc}
$\begin{array}{c}\text { Meyve } \\
\text { Türü }\end{array}$ & $\begin{array}{c}\text { Asşıa Gelme } \\
\text { Oranı (\%) }\end{array}$ & $\begin{array}{c}\text { Assı Tutma } \\
\text { Oranı (\%) }\end{array}$ \\
\hline Kayısı & 82.28 & 87.10 \\
Elma & 88.67 & 91.44 \\
Kiraz & 86.38 & 89.88 \\
Erik & 85.88 & 87.88 \\
Şeftali & 80.50 & 83.13 \\
Vişne & 89.00 & 87.75 \\
Badem & 85.00 & 86.88 \\
Ceviz & $---*$ & $---*$ \\
Armut & 86.28 & 90.21 \\
Ayva & 86.36 & 89.34 \\
Dut & 86.11 & 86.54 \\
Bă̆ Fidanı & $---*$ & $---*$ \\
\hline
\end{tabular}

* Bağ fidanı yerel fidan üreticiler tarafından başka şehirlerden aşılanmış olarak alınıp satılmaktadır.

İşletmelerde fidan üretiminde kullanılan anaçların yaz sonunda aşıya gelme oranları bütün meyve türlerinde \%80'in üzerinde gerçekleşirken, en yüksek aşıya gelme oranı \%89 ile vişnede gerçekleşmiş olup bunu $\% 88.67$ ile elma ve $\% 86.38$ ile kiraz anaçları izlemiştir.

İşletmelerin elde ettikleri aşı tutma oranlarına bakıldığında (çizelge 3) bu oranın bütün türlerde \%83'ün üzerinde olduğu görülmektedir. En yüksek aş1 tutma oranı $\% 91.44$ ile elmada, en düşük aş1 tutma oranı ise \%83.13 ile şeftalide belirlenmiştir.

Diğer taraftan, işletmelerde üretilen ceviz fidanları tohumdan yetiştirilmekte ve aşılanmadan satışa sunulmaktadır. Aşı1ı ceviz fidanlarının ise başka illerden getirilerek satışının yapıldığ 1 bildirilmiştir.

\section{Fidanlıklarda uygulanan kültürel işlemler}

Fidan üretiminin yapıldığı işletmelerde sulama durumu incelendiğinde İşletmelerden 14 tanesinin $(\% 87.50)$ damla sulama sistemini, 2 tanesinin (\%12.50) ise yağmurlama sistemini kullandıkları belirlenmiştir. Bunun yanında işletmelerin tamamında açık köklü fidan üretimi yapıldığı tespit edilmiştir.

Toprak işleme ve yabanc1 ot mücadelesinde işletmelerin tamamı üretim sırasında hem çapa motoru ile hem de elle çapalama yapmaktadır. Her fidan üretim döneminde ortalama 2 defa çapa motoru kullanılarak, 2 defa da elle çapalama yapıldığı bildirilmiştir.

Fidan üretimi yapan işletmelerin tamamı münavebe uygulamaktadır. İşletmelerin \%81.82'si münavebeyi kiraladıkları araziler üretim yapmaya devamederek gerçekleştirmektedir. Diğer taraftan münavebede yeşil gübreleme uygulaması hiç bir işletme tarafından uygulanmamaktadır.

Fidan işletmelerinin üretim alanlarında hastalık ve zararlılarla ilgili genel anlamda büyük bir problem görülmemekle birlikte Meyve ağacı dip kurtları (Capnodis spp.) ve Şeftali filiz güvesi (Anarsia lineatella) zararlılarının \%36.36 oranı ile en büyük sorun olduğu tespit edilmiştir. İşletmelerin $\% 90.91$ 'inin fidan üretiminin herhangi bir aşamasında hastalıktan etkilenmediği, \%36.36'sının da zararlılardan etkilenmediği belirlenmiştir. 
Hüseyin KARLIDAĞ ve Ark.

Çizelge 4. İşletmelerin fidan üretimi sırasında etkilendiği hastalık ve zararlı durumu

\begin{tabular}{|c|c|c|c|}
\hline & & İşletme Sayısı (adet) & Oran $(\%)$ \\
\hline \multirow{2}{*}{ Hastalık } & Kök çürüklüğü & 1 & 9.09 \\
\hline & Hastalık sorunu yok & 10 & 90.91 \\
\hline \multirow{5}{*}{ Zararlı } & Meyve ağacı dip kurtları & 4 & 36.36 \\
\hline & Şeftali filiz güvesi & 4 & 36.36 \\
\hline & Kırmızı örümcek & 2 & 18.18 \\
\hline & Elma pamuklu biti & 2 & 18.18 \\
\hline & Zararlı sorunu yok & 4 & 36.36 \\
\hline
\end{tabular}

\section{Üretilen Fidanların Muhafazası, Satış ve Pazarlama Durumu}

Üretim alanlarından sökülen fidanların genel olarak yörede toprak ve kumda hendeklendikleri tespit edilmiştir. İşletmelerin $\% 75$ 'inin sökümden sonra fidanları toprakta hendekledikleri ve bu şekilde ortalama 23.83 gün muhafaza ettikleri belirlenmiştir. Dört işletme yani işletmelerin \%25'inin ise sökülen fidanları kumda hendekledikleri ve hendeklenmiş fidanları ortalama 13.75 gün muhafaza ettikleri bildirilmiştir.
İşletmelerde fidan üretimi hem sertifikalı hem de sertifikasız olarak yapılmaktadır. Yörede fidan üretimi yapan 16 işletmeden 12 işletme hem sertifikalı hem de sertifikasız (ceviz çögürü) üretim gerçekleştirmektedir. Sertifikasız ortalama ceviz fidan fiyatı 7.58 TL olarak belirlenmiştir. Sert ve yumuşak çekirdekli meyve türlerine ait en yüksek ve en düşük sertifikalı fidan satış fiyatları sirasiyla $6.50 \mathrm{TL}$ (kiraz), $4.0 \mathrm{TL}$ (kayıs1) ve 4.75 TL (armut ve ayva), 4.33 TL (elma) olarak bildirilmiştir (Çizelge 5).

Çizelge 5. İşletmelerde meyve çeşitlerine göre ortalama fidan fiyatları ve standart sapma değerleri

\begin{tabular}{lcc}
\hline Fidan Türü & Fiyat (TL) & Standart Sapma (TL) \\
\hline Kayısı & 4.00 & 0.91 \\
Elma & 4.33 & 1.61 \\
Kiraz & 6.50 & 3.53 \\
Erik & 4.82 & 1.65 \\
Şeftali & 4.94 & 1.74 \\
Vişne & 4.82 & 2.02 \\
Ceviz & 7.58 & 3.93 \\
Badem & 4.94 & 2.02 \\
Armut & 4.75 & 1.93 \\
Ayva & 4.75 & 1.55 \\
Dut & 4.75 & $0 *$ \\
Bağ & 2.83 & 1.06 \\
\hline
\end{tabular}

* Sadece bir işletme tarafından satıldığı için standart sapma olmamıştır.

Üretilen fidanların büyük bir bölümü il sınırları içerisinde pazarlanmaktadır. Bu bağlamda üretim yapan firmaların fidan satışlarının yaklaşık \%67'lik kısmını Malatya'da gerçekleştirdiği belirlenmiştir. Bunun yanında toplamda \%17'lik satışın Elazığ, Kahramanmaraş ve Sivas illerine yapıldığ 1 tespit edilmiştir. Geriye kalan yaklaşık \%17'lik fidan satışının ise Erzincan, Erzurum,
Tunceli, Bingöl, Muş, Siirt ve Van illerine yapıldığ 1 bildirilmiştir.

\section{Sorunlar ve Çözüm Önerileri}

Çalışmanın yürütüldüğü fidan işletmelerinin sorunları 10 başl1kta toplanabilmiştir. Buna göre işletmelerin sorunları ve bunları sorun olarak gören işletmelerin oranları Çizelge 6' da verilmiştir. 


\begin{tabular}{lcc}
\multicolumn{1}{c}{ Sorunlar } & \multicolumn{2}{c}{ İşletme } \\
\cline { 2 - 3 } & $\begin{array}{c}\text { Sayısı } \\
\text { (adet) }\end{array}$ & $\begin{array}{c}\text { Oran } \\
(\%)\end{array}$ \\
\hline - Yerel bazda fidan üretici birliğinin olmayışı & 16 & 100.00 \\
- Kayıt dışı (korsan) fidancıların varlığı & 16 & 100.00 \\
- Maliyet - satış fiyatı dengesinin rekabetten dolayı oluşturulamaması & 16 & 100.00 \\
- Dişarıdan fidan girişinde kontrol mekanizamasının yetersizlĭği & 14 & 87.50 \\
- Fidan üretimine yönelik devlet desteğinin olmayışı & 14 & 87.50 \\
- Fiyat istikrarının olmayışı & 12 & 75.00 \\
- Fidan satış yerlerinin düzensizliği ve altyapının olmaması & 10 & 62.50 \\
- Fidan üreticisi-denetleyen kurum ve kontrolör zincirinde yaşanan sorunlar & 3 & 18.75 \\
- Anaç parselinin olmayışı & 3 & 18.75 \\
- Bilimsel değil ticari yaklaşım (fidan üreticileri için) & 1 & 6.25 \\
\hline
\end{tabular}

Yerel bazda fidan üretici birliklerinin olmayışı, kayıt dışı fidancıların pazarda etkin olması ve buna bağlı olarak maliyet ile pazar fiyatı dengesinin oluşturulamaması ankete katılan bütün işletmeler tarafından en önemli sorunlar olarak vurgulanmıştır. Fidan üretici birliklerinin oluşturulamamasından dolayı üretici sorunlarının ilgili makamlara ulaştırılamamasına neden olduğu gibi, üreticiler arasında fiyat istikrarının sağlanamaması sonucunu ortaya çıkardı̆̆ 1 bildirilmiştir.

Her ne kadar Şarka virüsünün yayılma tehlikesi nedeniyle (Gıda, Tarım ve Hayvancılık Bakanlığı tarafından yayınlanan, "Şarka Hastalığ1 İle Mücadele Hakkında Talimat" çerçevesinde sert çekirdekli fidanların Elazı̆̆ Şanlıurfa illeri dışından Malatya'ya girişi yasak olsa da, üreticiler yasal olmayan yollardan önemli miktarlarda fidan girişinin gerçekleştiğini belirtmişlerdir. $\mathrm{Bu}$ anlamda yasal takip ve kontrolün yetersizliğinden büyük ölçüde yakınmışlardır. Yukarıda belirtilen nedenlerden dolayı oluşan boşluktan dolayı kayıt dışı fidancılar için açık bir pazarlama alanının oluşmasına neden olduğu bildirilmiştir. Gıda, Tarım ve Hayvancılık Bakanlığı'nın denetlemede ve üretimi kayıt altına almada daha titiz hareket etmesi bu problemin giderilmesinde önemli bir rol oynayabilecektir. Yine bakanlık desteklemelerinin fidan üreticilerine dolaylı olarak yapıldığı (bahçe kurulumu sırasında sertifikalı fidan kullanımını teşvik etmesi), bu nedenle de fidan üreticilerinin üretim standartlarının düşük olduğu vurgulanmıştır. İlgili belediyelerin fidan üreticileri için satış yerleri oluşturmada geç kaldığına ve oluşturulan satış yerlerinin altyapılarının yetersizliğine fidan üreticilerinin \%63.63'ü tarafından dikkat çekilmiş̧tir.

\section{SONUÇ}

Çalışma kapsamında yapılan incelemeler sonucunda Malatya'da meyve fidanı yetiştiriciliği açısından; fiyat istikrarsızlı̆̆ının ve maliyet satış fiyatı dengesinin oluşmamasının en önemli sorunlar olduğu, bu sorunların temel olarak üretici birliklerinin yetersizliği, fidan satış yerlerinin düzensizliği, kayıt dış1 fidan satışının yaygınlığı, fidan üreticisi işletmelerin küçük ölçekli olması, klonal anaç kullanımının yaygın olmaması gibi nedenlerden kaynaklandığ yanında anaç parselinin olmaması ve şehir dışından kontrolsüz fidan girişlerinin yaygın olmasının önemli tehditler oluşturduğu belirlenmiştir. Fidan üretiminde, satışında ve temininde ticari yaklaşım yerine bilimsel yaklaşımın öncelenmesi, yerel bazda üretici birliklerinin yaygınlaştırılması, fidan üretiminin devlet tarafından desteklenmesi, şehir dışından kontrolsüz fidan girişinin ve kayıt dışı fidan üretim ve satışının denetim mekanizmalarının iyileştirilmesi alınabilecek en önemli tedbirler olarak önerilmiştir. 


\section{KAYNAKLAR}

Anonim, 2012. T.C. Gıda Tarım ve Hayvancılık Bakanlığı Bitkisel Üretim Genel Müdürlüğü (BÜGEM) kayıtları, Ankara.

Anonim, 2014. T.C. Ekonomi Bakanlığı yaş meyve ve sebze sektörü raporu, Ankara.

Büyükarıkan U, Büyükarıkan B, 2014. Türkiye'de meyve fidanı üretiminin mevcut durumu üzerine bir araştırma. MKU Ziraat Fakültesi Dergisi, 19: 16-25.

Gençtan T, Tugay ME, Geçit HH, Bozkurt B, Ergun E, Ekiz H, Yalvaç K, Gevrek MN, Elçi A, Balkan A, 2003. Türkiye'de tohumluk, fide ve fidan üretimi ve kullanımı. Ziraat Mühendisleri Odası Yayınlar1, 2: 803-823.
Küçüker E, Özkan Y, 2012. Bodur ve yarı bodur sistemli elma yetiştiriciliğinin ekonomik analizi. Iğdır Üniversitesi Fen Bilimleri Enstitüsü Dergisi, 2(3): 9-16.

Söylemezoğlu G, Dumanoğlu H, Çelik H, Kunter B, Atıcı A, Tahmaz H, 2010. Türkiye'de asma ve meyve fidanı üretimi ve kullanımı. Türkiye Ziraat Mühendisliği VII. Teknik Kongresi, 11-15 Ocak 2010, Ankara.

Yıldırım AN, Koyuncu F, 2005. Isparta ili meyve fidancılığ üzerine bir çalışma. Derim, 22: 20-28. 